\title{
Tsafon
}

Revue d'études juives du Nord

$80 \mid 2020$

Varia

\section{Brudny Michelle-Irène, Les noms de Vilno}

\section{Danielle Delmaire}

\section{(2) OpenEdition \\ Journals}

Édition électronique

URL : https://journals.openedition.org/tsafon/3487

DOI : $10.4000 /$ tsafon.3487

ISSN : 2609-6420

\section{Éditeur}

Association Jean-Marie Delmaire

Édition imprimée

Date de publication : 1 décembre 2020

Pagination : 184-185

ISSN : 1149-6630

\section{Référence électronique}

Danielle Delmaire, «Brudny Michelle-Irène, Les noms de Vilno », Tsafon [En ligne], 80 | 2020, mis en ligne le 01 décembre 2020, consulté le 24 juin 2021. URL : http://journals.openedition.org/tsafon/3487 ; DOI : https://doi.org/10.4000/tsafon.3487

Ce document a été généré automatiquement le 24 juin 2021.

Tsafon. Revues d'études juives du Nord 


\title{
Brudny Michelle-Irène, Les noms de Vilno
}

\author{
Danielle Delmaire
}

\section{RÉFÉRENCE}

Brudny Michelle-Irène, Les noms de Vilno, éd. Le Temps, 2020, 121 p.

1 Fille de résistants communistes originaires de Vilno, devenue philosophe et universitaire, Michelle-Irène Brudny revient sur le parcours de ses parents en essayant de restituer la trame de cette toile qu'ils ont tissée autour d'elle, dans son enfance et sa vie d'adulte. À la manière d'autres enfants de juifs persécutés pendant la guerre, elle place ses pas sur les traces de ses parents. Et elle le fait à la troisième personne, comme pour prendre des distances vis à vis de son récit tout en s'y incrustant. Volontairement, elle ne laisse pas le lecteur dupe. Georges Waysand (Profession du père, fusillé, lire la rubrique «Lecture » de ce numéro) pratique aussi cette distanciation mais en utilisant la seconde personne au lieu de la troisième, il parle à lui-même, tandis que M-I Brudny décrit les réactions d'un autre moi.

2 Et que cherche-t-elle? À travers les souvenirs de N. qui sont les siens, elle restitue lentement et de manière fragmentaire, parfois heurtée, la vie de ses parents, depuis Vilno jusqu'à ce couple dont elle est le fruit. Le lecteur est invité à la suivre dans ses investigations, fructueuses parfois, décevantes aussi et très souvent surprenantes. Tout ne lui a pas été raconté du vivant de ses parents. Toutefois, l'on retrouve avec bonheur la Vilno de Sutzkever et d'autres juifs moins connus, les pérégrinations vers l'Afrique $\mathrm{du}$ Sud et le mariage blanc qui permettent d'obtenir la nationalité britannique et de passer à travers les mailles du filet répressif en France.

3 N. (M-I Brudny) obtient l'aide des historiens (Henri Minczeles) ou d'éditeurs de mémoire (Muriel Chochois qui a publié les souvenirs d'Asia Turgel dans le hors série ${ }^{\circ}$ 9 de Tsafon). Les souvenirs et la mémoire sont désormais avivés par la génération des 
enfants qui recherchent leurs parents ou grands-parents (Ivan Jablonka, Philippe Sands avec Retour à Lemberg, Georges Waysand).

4 M-I Brudny a produit un livre qui se lit avec bonheur malgré le sujet sombre très souvent. Le lecteur est tenu en haleine au gré des enchantements et des déboires de $\mathrm{N}$. au cours de sa quête. Un léger regret toutefois : on aurait aimé lire une légende sous les photos. 